\title{
An orange fluorescent protein tagging system for real-time pollen tracking
}

\author{
J Hollis Rice ${ }^{1}$, Reginald J Millwood ${ }^{1}$, Richard E Mundell², Orlando D Chambers², Laura L Abercrombie', \\ H Maelor Davies ${ }^{3}$ and C Neal Stewart Jr ${ }^{1 *}$
}

\begin{abstract}
Background: Monitoring gene flow could be important for future transgenic crops, such as those producing plant-made-pharmaceuticals (PMPs) in open field production. A Nicotiana hybrid (Nicotiana. tabacum $\times$ Nicotiana glauca) shows limited male fertility and could be used as a bioconfined PMP platform. Effective assessment of gene flow from these plants is augmented with methods that utilize fluorescent proteins for transgenic pollen identification.

Results: We report the generation of a pollen tagging system utilizing an orange fluorescent protein to monitor pollen flow and as a visual assessment of transgene zygosity of the parent plant. This system was created to generate a tagged Nicotiana hybrid that could be used for the incidence of gene flow. Nicotiana tabacum 'TN 90' and Nicotiana glauca were successfully transformed via Agrobacterium tumefaciens to express the orange fluorescent protein gene, tdTomato-ER, in pollen and a green fluorescent protein gene, mgfp5-er, was expressed in vegetative structures of the plant. Hybrids were created that utilized the fluorescent proteins as a research tool for monitoring pollen movement and gene flow. Manual greenhouse crosses were used to assess hybrid sexual compatibility with N. tabacum, resulting in seed formation from hybrid pollination in $2 \%$ of crosses, which yielded non-viable seed. Pollen transfer to the hybrid formed seed in 19\% of crosses and 10 out of 12 viable progeny showed GFP expression.
\end{abstract}

Conclusion: The orange fluorescent protein is visible when expressed in the pollen of N. glauca, N. tabacum, and the Nicotiana hybrid, although hybrid pollen did not appear as bright as the parent lines. The hybrid plants, which show limited ability to outcross, could provide bioconfinement with the benefit of detectable pollen using this system. Fluorescent protein-tagging could be a valuable tool for breeding and in vivo ecological monitoring.

Keywords: Gene flow, Male-sterility, Plant made pharmaceuticals, Bioconfinement, Nicotiana, Green fluorescent protein (GFP), Orange fluorescent protein (OFP)

\section{Background}

Increased use of transgenic crops has prompted the necessity of monitoring transgene flow in agroecological systems. Previous investigations have ascertained the utility of gene flow tracking with fluorescent proteins (FPs) [1-4]. These studies have shown that green fluorescent protein (GFP) is an effective tool for the purpose of gene flow tracking and can be targeted to various organs and tissues within plants, including pollen. This technology, in effect, could be used in an environmental monitoring system, one of the many uses of FPs in plants [5]. One drawback of using native GFP as a marker in plants is the signal-to-noise ratio at GFP's maximum excitation

\footnotetext{
* Correspondence: nealstewart@utk.edu

${ }^{1}$ Department of Plant Sciences, University of Tennessee, 37996, Knoxville, TN, USA Full list of author information is available at the end of the article
}

wavelength of $395 \mathrm{~nm}$, often resulting in autofluorescence of plant tissue components [6]. Fluorescent proteins emitting in the red/orange spectrum that require longer wavelengths for excitation have lower levels of autoflorescence in plant tissues compared to blue or UV light [6]. One such widely used orange fluorescent protein (OFP), DsRed, is derived from Discosoma sp. its mutant variants have higher extinction coefficients and quantum yields [7]. Coral-derived FPs should be useful for monitoring gene flow.

Nicotiana tabacum (tobacco) and Brassica napus (canola) plants have been transformed to synthesize GFP in pollen, using pollen-specific promoters [1,4]. Long-range pollen tracking was conducted in canola species to assay pollen movement in real time (e.g. immediate detection of tagged pollen) using traps at various distances within

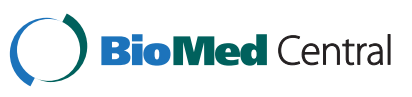

(c) 2013 Rice et al.; licensee BioMed Central Ltd. This is an Open Access article distributed under the terms of the Creative Commons Attribution License (http://creativecommons.org/licenses/by/2.0), which permits unrestricted use, distribution, and reproduction in any medium, provided the original work is properly cited. 
field and greenhouse experiments. This method is quicker and less laborious for determining pollen flow than analyzing progeny from recipient plants (e.g. antibiotic screening, PCR, FP screening) [8]. Drawing upon this previous body of work, it is logical to conceptualize a method to determine bioconfinement efficacy using FP tagging utilizing an improved fluorescent protein for plants.

The Nicotiana hybrid (Nicotiana tabacum $\times$ Nicotiana glauca), is highly sterile and prompted a further examination of bioconfinement through gene flow monitoring. Recently, we have shown that GFP tagging in vegetative plant tissues of this hybrid allows for gene tracking and assists with sterility assessments [9]. Here we describe a modified system to tag pollen that is applicable to a realtime assay of pollen flow from FP-tagged plants. Our goal was to engineer each Nicotiana species for pollenspecific expression of an OFP gene that also had vegetative tissues that expressed a GFP gene. The transgenic plants could then be crossed to obtain interspecific hybrid Nicotianas that had FP genes contributed from each parent. To achieve this goal, parent plants $N$. tabacum 'TN 90' and N. glauca were Agrobacterium-mediated transformed to synthesize the OFP tdTomato-ER in the pollen and bred to homozygosity, and then crossed to create the transgenic interspecific hybrid. Manual greenhouse crosses were performed to assess sexual compatibility and functionality of the system.

\section{Methods}

\section{Plants}

N. tabacum 'TN 90' used for transformation was from foundation seed lot \# 86-02-K-4A, N. tabacum 'MS TN 90' from foundation seed lot \# 86-03-KLC-15 is a male sterile variety of TN 90 that was used as a pollen recipient plant in crosses. $N$. tabacum 'SN 2108', a morphologically distinct variety from the TN 90 cultivar used as a pollen donor in greenhouse crosses, is an experimental line developed into 'KT D4'; all $N$. tabacum were obtained from the Kentucky Tobacco Seed Improvement Association, Inc. in Lexington, KY, USA. $\left(38^{\circ} 8^{\prime} \mathrm{N}, 84^{\circ}\right.$ $29^{\prime}$ W). N. glauca used for transformation was from the US National Plant Germplasm System (plant introduction 307908, accession TW55 from Peru).

\section{Transformation}

\section{Vector construction}

Two fluorescent proteins were used to mark plants. The mgfp5-er gene encodes a GFP that emits green light $\left(\lambda_{\max }=509 \mathrm{~nm}\right)$ when excited by wavelengths of blue (465 nm) or ultraviolet (UV; $395 \mathrm{~nm}$ ) light and targeted and retained in the endoplasmic reticulum (ER) within cells. GFP in transgenic plants is observable by UV light illumination in the dark or epifluorescence microscopy, and is quantifiable using fluorescence spectrometry
[10,11]. tdTomato-ER, is a DsRed variant that is a tandem dimer OFP $\left(\lambda_{\max }=581 \mathrm{~nm}\right.$ and excited by green light $(554 \mathrm{~nm})$ that is also retained in the ER $[7,12]$. To create dual FP marker vectors, the Gateway compatible vector backbone pMDC99, containing a hygromycin resistance cassette, and pMDC100, containing a kanamycin resistance cassette, were utilized as Gateway destination vectors [13]. An entry vector containing a pollen-specific promoter, LAT52 [14], driving expression of the OFP tdTomato-ER and a nos terminator was recombined with the destination vectors, creating the intermediate vectors pMDC99-tdTomato-ER and pMDC100-tdTomato-ER. Subsequently a GFP expression cassette (containing CaMV35S-mGFP5-ER-nosT) was amplified from pBIN19mGFP5-ER and cloned into the intermediate vectors, creating the binary vectors TD-GFP-H (containing hygromycin selection) and TD-GFP-K (containing kanamycin selection), respectively (Figure 1 ). These vectors were identical except for the antibiotic resistance genes to facilitate screening by using dual antibiotic selection after hybridization of Nicotiana species to incorporate both constructs into the $F_{1}$ hybrid.

\section{Generation of transgenic plants}

Plant transformation experiments were performed using Agrobacterium tumefaciens strain EHA 105 using the previously-described leaf disc method [15]. Sterilized leaf explants were soaked for $30 \mathrm{~min}$ in a mixture of Agrobacterium and liquid MS salts containing $\mathrm{B}_{5}$ vitamin (DBI). Transformed explants were then co-cultivated on solid DBI media for 2 days before being transferred to solid DBI containing Timentin ${ }^{\circ}(400 \mathrm{mg} / \mathrm{L})$ and either kanamycin $(200 \mathrm{mg} / \mathrm{L})$ or hygromycin $(50 \mathrm{mg} / \mathrm{L})$ for selection. Shoots generated from transformed callus were transferred to MS media containing respective selective antibiotics $[15,16]$. Shoots were maintained at $24^{\circ} \mathrm{C}$ under $16 / 8 \mathrm{~h}$ light/dark periods until rooting, then transferred to soil in standard 1020 flats divided in to 18 cells measuring $7.95 \mathrm{~cm} \times 7.94 \mathrm{~cm} \times 5.72 \mathrm{~cm}$ with humidity domes to allow for acclimation for approximately two weeks. Plants leaves were then assayed with a handheld UV light (UVP model B-100AP $100 \mathrm{~W}: 365 \mathrm{~nm}$ ) to detect differentiate between transgenic and nontransgenic plants as previously described [11]. The presence of the TD-GFP-H and TD-GFP-K inserts were confirmed in each $\mathrm{T}_{0}$ plant by DNA extraction and PCR to amplify mgfp5-er DNA (Figure 2) as previously described $[1,17]$. Plants that were confirmed visually and with PCR to be transgenic were transferred into $4 \mathrm{~L}$ pots in a

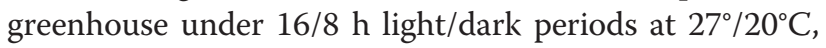
respectively. Seeds were harvested from each plant by covering flowers with breathable mesh pollination bags (DelStar Technologies, Inc., Middleton, DE, USA) and periodically manually shaken until seed pods developed 


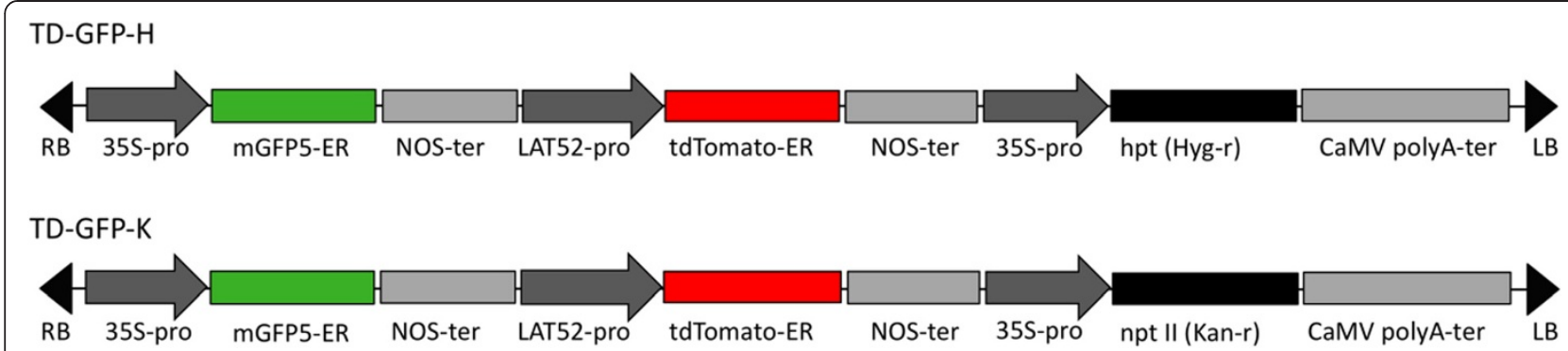

Figure 1 Cassettes used in transformation. Cassettes TD-GFP- H and TD-GFP-K were used in transformation of N. glauca and N. tabacum 'TN $90^{\prime}$ with A. tumefaciens strain EHA105. Vectors are identical except for the hpt gene present in TD-GFP-H and the npt // gene present in TD-GFP-K.

and were harvested. In all, 20 events were generated per construct per species.

\section{Hybrid Nicotiana production}

Plants were bred to obtain lines that had both constructs for a complete tracking of pollen. To ensure multiple transgene copies were stacked into the hybrid, our goal was to produce hybrids containing one TD-GFP-K and one TD-GFP-H construct, using dual antibiotic screening to ensure to select hybrids that were transgenic for each construct.

\section{Fluoresence measurements and observations}

Brightly fluorescent $T_{0}$ plants, as determined by visual observation for GFP, were selected for analysis and further breeding; ten $\mathrm{T}_{1}$ TN 90 GFP-H lines and eight $N$. glauca $\mathrm{T}_{1}$ TD-GFP-K lines were selected. $\mathrm{T}_{1}$ seeds were germinated and handheld UV light was used to select the brightest GFP-expressing seedlings. GFP fluorescence was measured by a spectrofluorometer (Fluorolog ${ }^{\circledR}-3$ HORIBA Jobin Yvon, Edison, NJ, USA)[11,18] and analyzed with its software (FluorEssence ${ }^{\text {тм }}$ Version 2.5.2.0.HORIBA Jobin Yvon, Edison, NJ, USA) to quantify average fluorescence (photon counts per second) from each $\mathrm{T}_{1}$ line (Figures 3

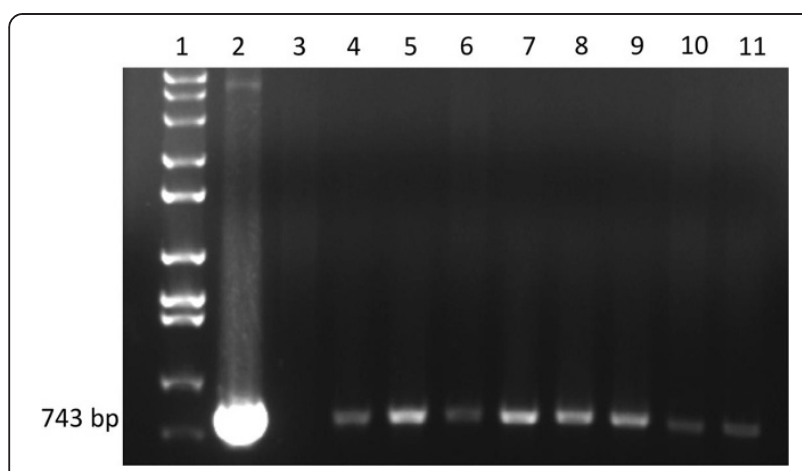

Figure 2 PCR analysis of $T_{0}$ TN 90 plants transformed with TD-GFP-H. Lane 1: DNA marker, Lane 2: purified mGFP5ER plasmid as a positive control. Lanes 3-11: genomic DNA from putative transgenic TN 90. The 743 bp band present in lanes 4 through 11 confirmed transgene presence in plants. All other transgenic events showed similar results. and 4). Individual plants were selected that had the highest measured fluorescence, and thus, were most likely to be homozygous for the TD-GFP-K or TD-GFP-H inserts [18]. When $T_{1}$ plants flowered, pollen was taken from each plant, suspended in $200 \mu \mathrm{l}$ of water, and $15 \mu \mathrm{l}$ of the suspension transferred to a microscope slide and observed under an epifluorescent BX 51 microscope (Olympus Corporation, Shinjuku, Tokyo, Japan). A Texas Red ${ }^{\odot} /$ Cy3.5 (TxRed) filter set (Chroma Technology Corporation, Bellows Falls, VT, USA) was used to view fluorescent pollen grains. The field of view was captured by a digital camera (Olympus Q Color 3) and Qcapture imaging system (Q Imaging Corp., Burnaby, Canada) (Figure 5).

\section{Transgenic line selection}

With the assumption of a single insertion event, transgene zygosity was estimated using epifluorescent microscopy. Plants with $100 \%$ fluorescent pollen (deemed homozygous) were bagged and self-fertilized as previously described. In addition to the FP pollen assay, we used progeny assays to assure that we selected homozygosity of each $\mathrm{T}_{2}$ line. Germinated seed were screened with a handheld UV light to determine zygosity of each $\mathrm{T}_{2}$ line (using ratios of GFP to non-GFP plants). Seeds of each $\mathrm{T}_{2}$ line were also screened for inheritance of antibiotic resistance genes by germination on MS media [15] containing kanamycin (200 mg/L) or hygromycin $(50 \mathrm{mg} / \mathrm{L})$ wherein observation of plant health allowed for determination of segregation; 100\% survival indicated a homozygous line for selection. The selected transgenic $\mathrm{T}_{2}$ lines, TN 90 TD-GFP-H and $N$. glauca TD-GFP-K, were crossed (TN 90 TD-GFP-H $\times N$. glauca TD-GFP-K). Hybrid lines derived from parents lines transformed with the TD-GFP-K/TD-GFP-H constructs were named 'Hybrid OFP' plants. These hybrid seeds were germinated on MSO media containing both kanamycin (200 mg/L) and hygromycin (50 mg/L) to ensure both constructs were integrated into the hybrid genome.

\section{Fertility assessment in hybrids}

Manual crosses were conducted in a greenhouse in Lexington, Kentucky (Table 1). Hybrid OFP plants were 


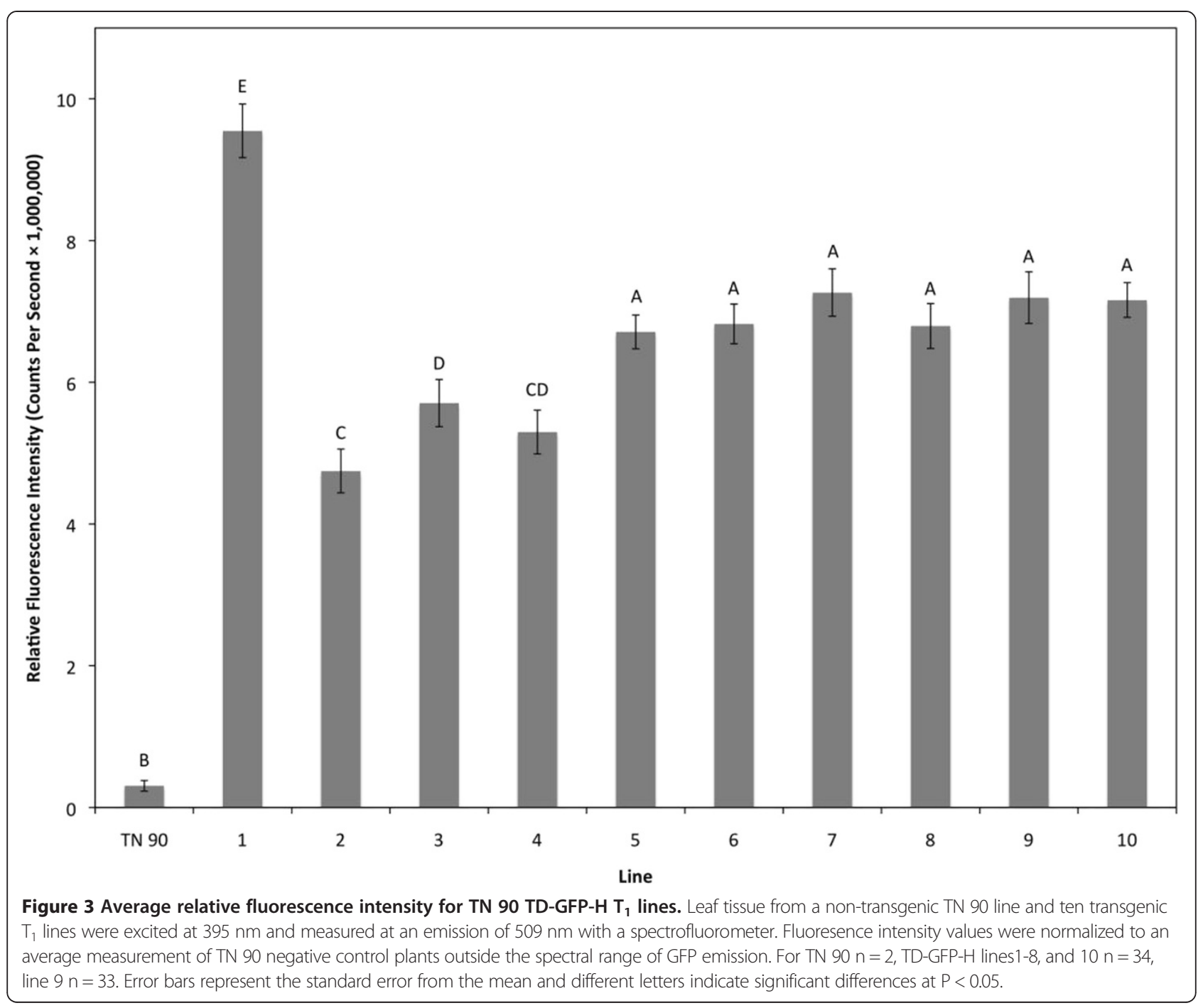

crossed with the male sterile $N$. tabacum 'MS TN 90' to determine hybrid outcrossing potential and transgene transmission rates. To evaluate female fertility, SN 2108, a pollen donor was crossed to hybrid OFP plants, which were emasculated prior to crossing. For both types of crosses, 8 pairs of plants were crossed, with 12 crosses per pair except of one pair (hybrid OFP $\times$ SN 2108) of plants where 11 crosses were made. Seeds from crosses were germinated and screened visually as previously described for GFP presence. Fertilility rates were determined by the number of attempted crosses divided by the total number of crosses attempted. Detectable gene flow was determined by dividing the total number of germinated GFP expressing seed by the total number of surviving seedlings.

\section{Statistical analysis}

All analysis of variance (ANOVA) routines were performed using SAS (Version 9.3 SAS Institute Inc, Cary,
NC, USA) using the MIXED procedure with a significance level of $\mathrm{p}<0.05$. When ANOVA results were found to be statistically significant, the least significant differences were used for mean separations.

\section{Results and discussion}

Transformation of N. tabacum 'TN 90' and N. glauca were successful except for $N$. glauca TD-GFP-H where multiple attempts failed to produce hygromycinresistant plants. GFP was visible in leaves, stems, and roots (data not shown) and OFP was visible in pollen under a microscope (Figure 5) with the aforementioned filter set. GFP, regulated by the CaMV $35 \mathrm{~S}$ promoter, was not visible in pollen in accordance with previous findings [19,20]. Highly fluorescent individual plants from the most fluorescent $N$. glauca TD-GFP-K lines were crossed with highly fluorescent TN 90 TD-GFP-H lines to ensure hybrids had both antibiotic resistance 


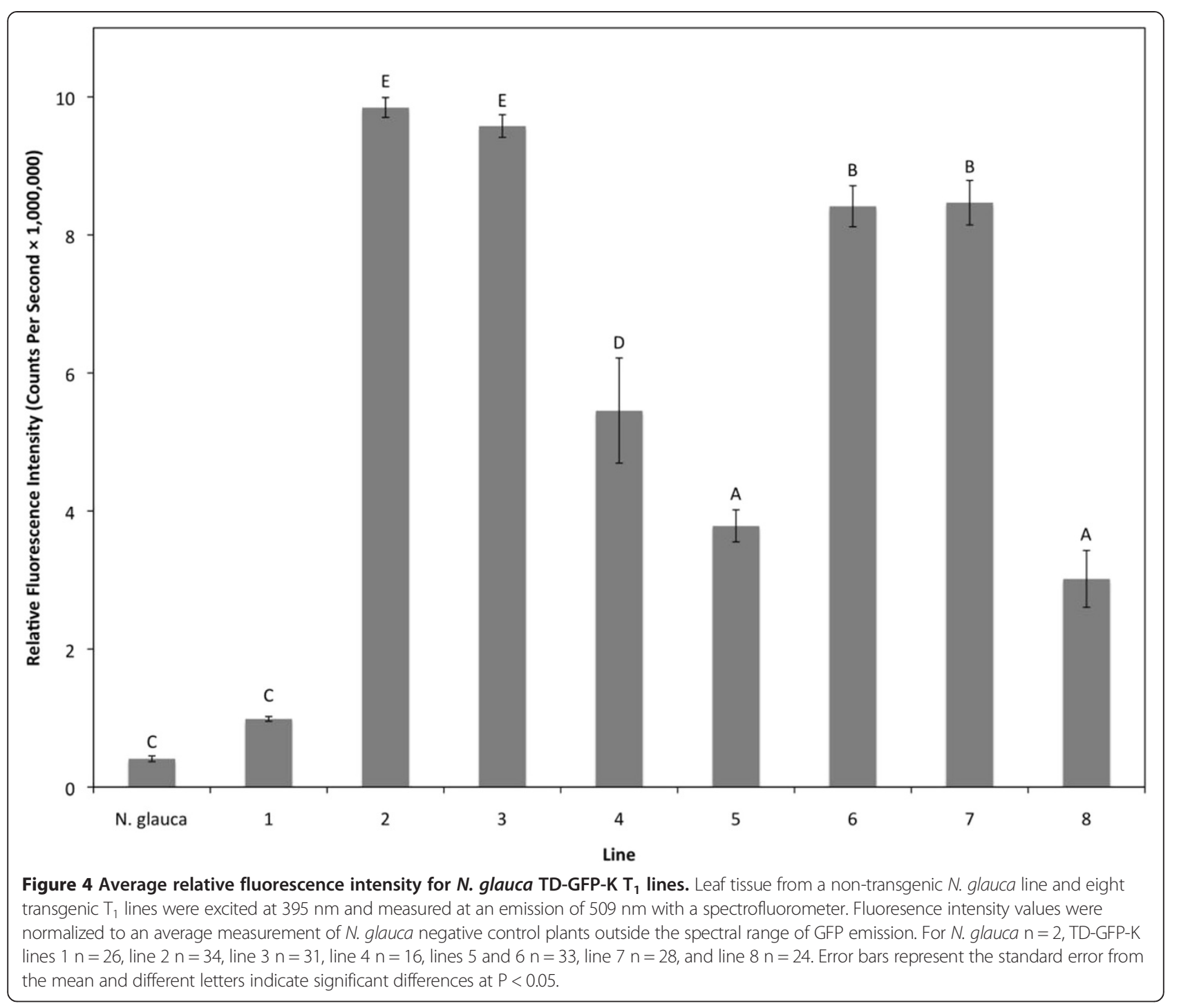

genes and would fluoresce brightly, thereby facilitating detection. Since we selected plants on the basis of green-fluorescence shoots, it is not surprising that pollen orange fluorescence was also bright in these lines. Hybrid OFP lines were 100\% resistant to kanamycin and hygromycin when screened on MSO media containing both antibiotics (data not shown), indicating inclusion of both cassettes into the $F_{1}$ hybrids.

Manual plant crosses revealed that the hybrids were able to backcross to a non-transgenic male sterile $N$. tabacum 'MS TN 90' (Table 1), forming entirely nonviable seed in $2 \%$ of the crosses ( $98 \%$ of the crosses produced no seed), thus restricting detectable transgene transmission rates in progeny to $0 \%$. This result was in contrast to our previous findings where few viable seeds ( 2 out of 445 seeds from 96 crosses) were generated from a similar (MS TN $90 \times$ hybrid) cross that employed a different construct using mgfp5-er [9]. In addition, we have determined that male fertility varies among hybrid lines from 0 to 3\% [9]. When the fertile line, SN 2108, was used to pollinate hybrid OFP plants, limited seed set (19\% of crosses) was observed. Only 10 germinated seedlings out of 12 expressed GFP, (83\% detectable transgene transmission), indicating that transgenes might be segregating out of some hybrid OFP $\times$ SN 2108 progeny.

It was unknown if tdTomato-ER would be visible in the pollen of the Nicotiana hybrid as the plant largely produces immature pollen where many pollen mother cells cease to develop past the tetrad stage [21]. Many of the immature pollen grains apparently did not synthesize sufficient tdTomato-ER for visual detection. The FP was only obvious in larger, more mature hybrid OFP pollen and did not appear to fluoresce as brightly as TN 90 TD-GFP-K and N. glauca TD-GFP-H. The pollenspecific promoter $L A T 52$, regulates gene expression during microspore mitosis, allowing transcription until 


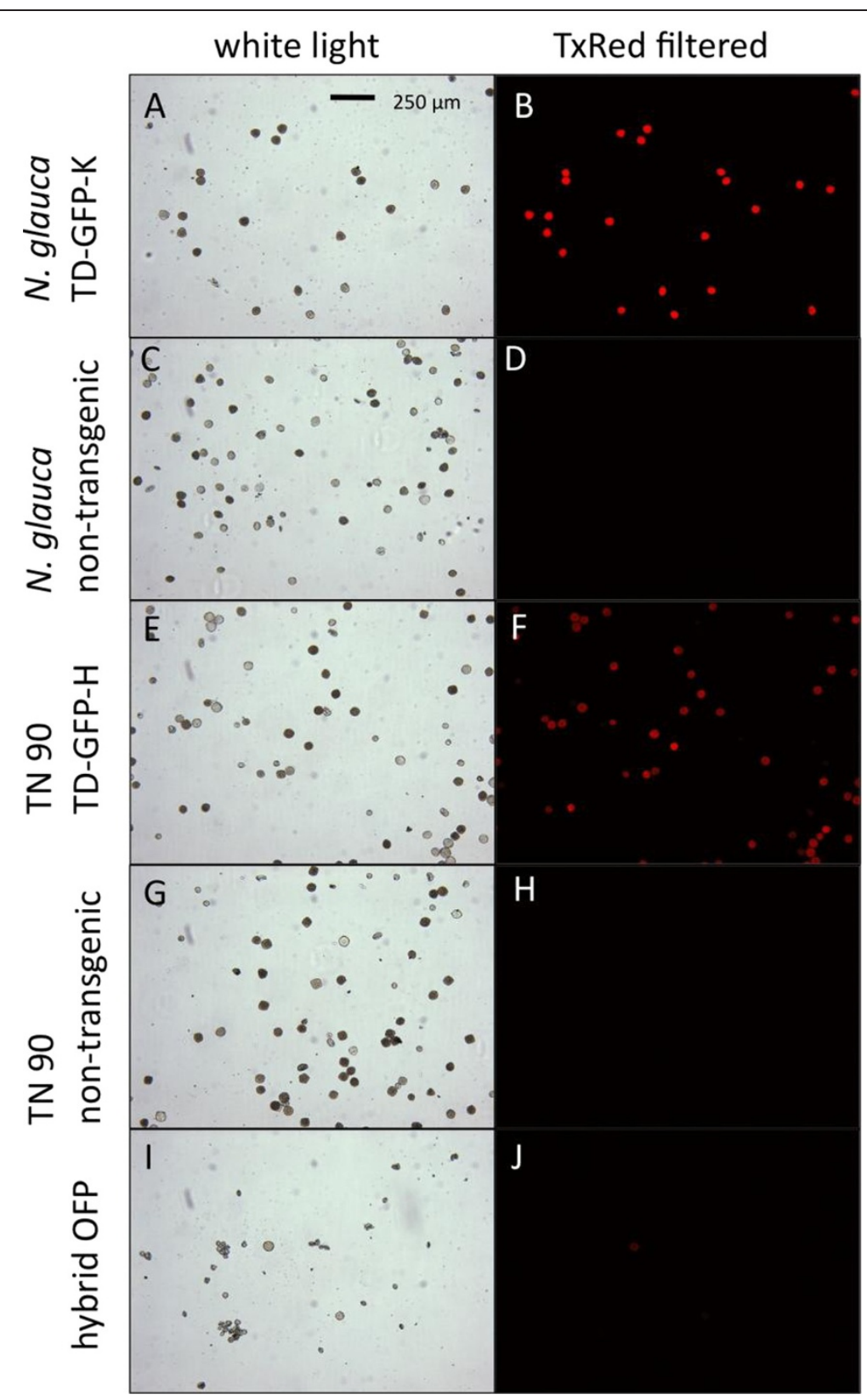

Figure 5 Fluorescent protein visualization in pollen. Orange fluorescent protein-tagged pollen as viewed under an epifluorescent microscope at 100x. N. glauca and TN 90 plants have been bred for homozygosity of tdTomato-ER, resulting in hybrid OFP plants. All white light images (A), (C), (E), (G), and (I) were captured at 80 ms exposure time. Panels (B), (D), (F), (H), and (J) are epifluorescent microscopy images using green light excitation and orange light emission. Panels (B) and (D) were captures at $50 \mathrm{~ms}$ exposure time. Panels (F) and (H) were captured at $80 \mathrm{~ms}$ exposure time. Panel $(\boldsymbol{J})$ was captured at $180 \mathrm{~ms}$ exposure time.

Table 1 Greenhouse crosses performed with hybrid OFP plants

\begin{tabular}{cccccccccc}
\hline Genotypes $^{\mathbf{a}}$ & $\begin{array}{c}\text { Plants } \\
\text { crossed }^{\mathbf{b}}\end{array}$ & $\begin{array}{c}\text { Total } \\
\text { crosses }^{\mathbf{c}}\end{array}$ & $\begin{array}{c}\text { Crosses } \\
\text { forming seed }^{2}\end{array}$ & $\begin{array}{c}\text { Total seed } \\
\text { count }\end{array}$ & Germinated & Survived & $\begin{array}{c}\text { GFP } \\
\text { positive }\end{array}$ & $\begin{array}{c}\text { Fertilization } \\
\text { rate }\end{array}$ & $\begin{array}{c}\text { Detectable } \\
\text { gene flow }\end{array}$ \\
\hline (MS TN 90 $\times$ hybrid OFP) & $8: 8$ & 96 & 2 & 51 & 0 & N/A & N/A & $2 \%$ & $0 \%$ \\
(hybrid OFP $\times$ SN 2108) & $8: 8$ & 95 & 18 & 34 & 14 & 12 & 10 & $18 \%$ & $83 \%$ \\
\hline
\end{tabular}

${ }^{a}$ Crosses listed by (female $0 \times$ male $\left.{ }^{\Uparrow}\right)$.

${ }^{b}$ Refers to numbers of each plant used in crosses with respect to the plant order in the genotypes column. 12 crosses were attempted between each pair of plants, except one pair of hybrid OFP and SN 2108 where 11 crosses were made.

${ }^{c} \mathrm{~A}$ 'cross' is constituted by a pollen transfer from one plant to the flower of another plant. 
anthesis $[14,22]$. Our observation of few mature fluorescent pollen grains produced in the hybrids demonstrates that the interspecific hybrid system could be a viable candidate for transgene bioconfinement.

\section{Conclusions}

A bright orange fluorescent protein, tdTomato-ER, can be synthesized in pollen when its gene is under the control of the LAT52 pollen promoter. Fluorescently-tagged pollen is highly distinguishable from non-tagged pollen, and shows low autofluorescence. The plants produced in this study further increase the number of tools available for gene flow studies. Crossing studies demonstrated that hybrid OFP plants had low fertility and provided bioconfinement by limiting successful crosses made to the maternal line, $N$. tabacum. As pollen tracking is possible with this fluorescently tagged hybrid, more research is needed to determine the efficacy of pollen detection with this system and how it relates to bioconfinement in a field setting.

\section{Competing interests}

The authors declare that they have no competing interests.

\section{Authors' contributions}

JHR: Performed all plant transformation experiments and transgenic line analysis, and drafted the document: REM: Conceived portions of the study, bred the original interspecific hybrid, produced the experimental hybrids, and performed manual greenhouse crosses. RJM: Coordinated the study and assisted with analysis. LLA created the vectors for transformation. ODC: Conceived portions of the study and assisted with coordination and execution of the study. HMD: Conceived portions of the study, coordinated the study, and provided critical review. CNS: Conceived portions of the study, coordinated the study, and assisted with revisions. All authors read and approved the final manuscript.

\section{Acknowledgements}

The authors wish to thank Charleson Poovaiah and Christy Rose for assistance in plant transformation experiments and Justin McDuffie for assistance with data collection. This study was funded by the NIFA Biotechnology Risk Assessment Grant Program and all research was conducted in compliance of USDA-APHIS-BRS regulations.

\footnotetext{
Author details

'Department of Plant Sciences, University of Tennessee, 37996, Knoxville, TN, USA. ${ }^{2}$ Kentucky Tobacco Research \& Development Center, University of Kentucky, 40546 Lexington, KY, USA. ${ }^{3}$ Department of Plant \& Soil Sciences, University of Kentucky, 40546 Lexington, KY, USA.
}

Received: 30 April 2013 Accepted: 24 September 2013

Published: 27 September 2013

\section{References}

1. Hudson LC, Chamberlain D, Stewart CN Jr: GFP-tagged pollen to monitor pollen flow of transgenic plants. Mol Ecol Notes 2001, 1:321-324.

2. Halfhill MD, Richards HA, Mabon SA, Stewart CN Jr: Expression of GFP and Bt transgenes in Brassica napus and hybridization with Brassica rapa. Theor Appl Genet 2001, 103:659-667.

3. Halfhill MD, Zhu B, Warwick SI, Raymer PL, Millwood RJ, Weissinger AK, Stewart CN Jr: Hybridization and backcrossing between transgenic oilseed rape and two related weed species under field conditions. Environ Biosafety Res 2004, 3:73-81.

4. Moon HS, Halfhill MD, Hudson LC, Millwood RJ, Stewart CN Jr: Expression of green fluorescent protein in pollen of oilseed rape (Brassica napus L.) and its utility for assessing pollen movement in the field. Biotechnol $\mathrm{J}$ 2006, 1:1147-1152.

5. Millwood RJ, Moon HS, Stewart CN Jr: Fluorescent proteins in transgenic plants. Rev in Fluorescence 2008, 2010:387-403.

6. Stewart CN Jr: Go with the glow: fluorescent proteins to light transgenic organisms. Trends Biotechnol 2006, 24:155-162.

7. Shaner NC, Campbell RE, Steinbach PA, Giepmans BN, Palmer AE, Tsien RY: Improved monomeric red, orange and yellow fluorescent proteins derived from Discosoma sp. red fluorescent protein. Nat Biotechnol 2004, 22:1567-1572.

8. Wei W, Kwit C, Millwood RJ, Moon HS, Stewart CN Jr: Assessment and detection of gene flow. In Plant Gene Containment. Edited by Oliver MJ, Yi L. Lincoln: Wiley-Blackwell; 2012:27-37.

9. Rice JH, Mundell RE, Millwood RJ, Chambers OD, Stewart CN Jr, Davies HM: Assessing the bioconfinement potential of a Nicotiana hybrid platform for use in plant molecular farming applications. BMC Biotechnol 2013, 13:63.

10. Morise H, Shimomura O, Johnson FH, Winant J: Intermolecular energy transfer in the bioluminescent system of Aequorea. Biochemistry 1974, $13: 2656-2662$.

11. Millwood RJ, Halfhill MD, Harkins D, Russotti R, Stewart CN Jr: Instrumentation and methodology for quantifying GFP fluorescence in intact plant organs. Biotechniques 2003, 34:638-643.

12. Mann DGJ, Abercrombie LL, Rudis MR, Millwood RJ, Dunlap JR, Stewart CN $\mathrm{Jr}$ : Very bright orange fluorescent plants: endoplasmic reticulum targeting of orange fluorescent proteins as visual reporters in transgenic plants. BMC Biotechnol 2012, 12:17

13. Curtis MD, Grossniklaus U: A gateway cloning vector set for high-throughput functional analysis of genes in planta. Plant Physiol 2003, 133:462-469.

14. Twell D, Yamaguchi J, McCormick S: Pollen-specific gene expression in transgenic plants: coordinate regulation of two different tomato gene promoters during microsporogenesis. Development 1990, 109:705-713.

15. Horsch RB, Fry JE, Hoffmann NL, Eichholtz D, Rogers SG, Fraley RT: A simple and general method for transferring genes into plants. Science 1985, 227:1229-1231.

16. McCormick S, Niedermeyer J, Fry J, Barnason A, Horsch R, Fraley R: Leaf disc transformation of cultivated tomato (L. esculentum) using Agrobacterium tumefaciens. Plant Cell Rep 1986, 5:81-84.

17. Stewart CN Jr, Via LE: A rapid CTAB DNA isolation technique useful for RAPD fingerprinting and other PCR applications. Biotechniques 1993, 14:748-750.

18. Halfhill MD, Millwood RJ, Weissinger AK, Warwick SI, Stewart CN Jr: Additive transgene expression and genetic introgression in multiple greenfluorescent protein transgenic crop $\times$ weed hybrid generations. Theor Appl Genet 2003, 107:1533-1540.

19. Harper BK, Mabon SA, Leffel SM, Halfhill MD, Richards HA, Moyer KA, Stewart CN Jr: Green fluorescent protein as a marker for expression of a second gene in transgenic plants. Nat Biotechnol 1999, 17:1125-1129.

20. Harper BK, Stewart CN Jr: Patterns of green fluorescent protein expression in transgenic plants. Plant Mol Biol Report 2000, 18:141a-141i.

21. Trojak-Goluch A, Berbeć A: Cytological investigations of the interspecific hybrids of Nicotiana tabacum L. $\times$ N. glauca Grah. J App/ Genet 2003, 44:45-54.

22. Twell D, Wing R, Yamaguchi J, McCormick S: Isolation and expression of an anther-specific gene from tomato. Mol Gen Genet 1989, 217:240-245.

\section{doi:10.1186/1756-0500-6-383}

Cite this article as: Rice et al.: An orange fluorescent protein tagging system for real-time pollen tracking. BMC Research Notes 2013 6:383. 